\section{Factors identified with higher levels of career satisfaction of physicians in Andalusia, Spain}

\author{
Juan Nicolás Peña-Sánchez, 1 \\ Rein Lepnurm, 1 \\ José Miguel Morales-Asencio, ${ }^{2}$ \\ Ana Delgado, 3 Alicja Domagała, 4 \\ Maciej Górkiewicz ${ }^{4}$
}

1School of Public Health, University of Saskatchewan, Saskatoon, Canada;

2School of Health Sciences, University

of Malaga, Spain; ${ }^{3}$ Andalusian School

of Public Health, Granada, Spain;

4 Institute of Public Health, Jagiellonian

University, Krakow, Poland

\section{Abstract}

The satisfaction of physicians is a worldwide issue linked with the quality of health services; their satisfaction needs to be studied from a multi-dimensional perspective, considering lower- and higher-order needs. The objectives of this study were to: i) measure the career satisfaction of physicians; ii) identify differences in the dimensions of career satisfaction; and iii) test factors that affect higherand lower-order needs of satisfaction among physicians working in Andalusian hospitals (Spain). Forty-one percent of 299 eligible physicians participated in a study conducted in six selected hospitals. Physicians reported higher professional, inherent, and performance satisfaction than personal satisfaction. Foreign physicians reported higher levels of personal and performance satisfaction than local physicians, and those who received nonmonetary incentives had higher professional and performance satisfaction. In conclusion, physicians in the selected Andalusian hospitals reported low levels of personal satisfaction. Non-monetary incentives were more relevant to influence their career satisfaction. Further investigations are recommended to study differences in the career satisfaction between foreign and local physicians.

\section{Introduction}

Since the art of medicine is based on diagnostic abilities to provide good treatments, strategies to treat dissatisfaction among physicians should use the same approach. Treatments for doctors' unhappiness must be followed by adequate diagnoses and recognition of its causes. ${ }^{1}$ Dissatisfaction of physicians has been recognized as a worldwide phe- nomenon, ${ }^{1}$ and it has been linked with low levels of patient satisfaction, patient compliance with treatments, and quality of health services. $^{2}$ Furthermore, dissatisfaction of physicians has been associated with high levels of distress, ${ }^{3}$ leave direct patient care, $, 2,4,5$ burn-out and poor mental well-being. 2,6 However, health care systems tend to overlook or ignore indicators of physician well-being. ${ }^{7}$

Researchers have been studying factors associated with higher levels of satisfaction among physicians. ${ }^{8} 9$ In Spain, several studies have evaluated the satisfaction of physicians among certain groups of specialists using different perspectives; ${ }^{10-15}$ however, these studies are focused on the perspective of satisfaction with work. The satisfaction of physicians should have a multi-dimensional approach in order to evaluate their higher-order needs, ${ }^{16}$ like growth, life achievement, career development, autonomy, responsibility, creativity, selfesteem, and self-actualization, within Maslow's hierarchy of needs. ${ }^{17}$

The perspective of career satisfaction of physicians has been conceptualized into lower and higher order needs, where inherent and performance satisfaction capture higher level needs, and personal and professional dimensions capture lower level needs. ${ }^{16}$ The questionnaire, developed in Canada, ${ }^{16}$ to measure career satisfaction of physicians was adapted and validated with good psychometric measures among physicians in Andalusia, Spain;18 in-depth analyses of the Andalusian study are presented in this paper.

Subsequently, the objectives of this study were to: i) measure the career satisfaction of physicians working in hospitals of Andalusia, using the adapted instrument; ii) identify differences in the dimensions of career satisfaction; and iii) test factors affecting higher and lower order needs of the career satisfaction.

\section{Materials and Methods}

Data were drawn from a cross-sectional study conducted among physicians working in six hospitals of Andalusia, Spain, from November 2009 to February 2010. In total, 299 physicians were eligible to participate in the study, excluding residents and medical students. Eligible physicians were invited by email to complete an on-line questionnaire in Spanish, asking about their career satisfaction, work conditions, incentives, and demographics. Participants were informed about the objectives of the study and the identity confidentiality policy. The study received the ethics approval from the Ethics Commission for Research of the University of Granada and the Ethics Board of the College of Medicine of the University of Granada, as well as from the
Correspondence: Juan Nicolás Peña-Sánchez, School of Public Health, University of Saskatchewan, 104 Clinic Place, Saskatoon, SK S7N 5E5, Canada.

Tel.: +1.306.844.1484 - Fax: +1.306.966.2264.

E-mail: juan.nicolas.ps@usask.ca

Key words: physicians, career satisfaction, dimensions, motivational factors, Andalusia.

Acknowledgments: the authors would thank the physicians who participated in this study, as well as the administrative staff and directives of the hospitals who supported the development of this research. A special thank to Silvia BermedoCarrasco, José Francisco García-Gutiérrez, Michael Szafron, and Azalea Barrieses who provided their advices and support in the development of this manuscript. Preliminary results of this study were shared in a poster presentation at the 2012 Canadian Society for Epidemiology and Biostatistics National Student Conference in Saskatoon, Canada.

Contributions: JNPS led the design and development of the study, data collection and analysis, and manuscript preparation; RL participated in data analysis, interpretation, and manuscript preparation; JMMA and ADe contributed to the study design, development, and results interpretation; ADo and MG contributed in the data analysis.

Conflict of interests: the authors declare no potential conflict of interests.

Funding: this study is part of a Masters research; the student received funding for his studies from Fundación Colfuturo, Colombia. The "Internet y Salud" research group of the Andalusian School of Public Health, contributed with the license for the on-line data collection.

Received for publication: 27 March 2013.

Revision received: 30 April 2013.

Accepted for publication: 30 April 2013.

This work is licensed under a Creative Commons Attribution NonCommercial 3.0 License (CC BYNC 3.0).

(C)Copyright J.N. Peña-Sánchez et al., 2014

Licensee PAGEPress, Italy

Health Psychology Research 2014; 2:1527

doi:10.4081/hpr.2014.1527

Chair of the participant hospitals.

The selected instrument to measure career satisfaction has seventeen items; 16 specific items and one global item, all scored on 6 point scales from very dissatisfied to very satisfied. ${ }^{6}$ The items of the questionnaire, in English and Spanish, are presented in the Appendix. A standardized mean score for the full 16 items was calculated by totalizing the items and dividing by 16 , yielding an interval measure with a minimum of score of 1.00 to a maximum 
score of 6.00 . Similarly, mean scores were calculated for each of the four dimensions. ${ }^{16,18}$ The Friedman's ANOVA Test was used to determine rank differences across the four dimensions of career satisfaction, and the Wilcoxon Matched-Pairs Signed Rank Test was used as post-hoc analysis to identify differences between the dimensions.

A logistic regression model was built to identify associated factors with the probability that a physician reports a higher level of career satisfaction. The dependent variable was $1=$ score higher than the group median, and $0=$ score equal or lower than the group median. The independent variables in the model were personal features (gender, age, and being a foreign physician), career features (speciality by broad groups, having a second speciality, and years of experience), work features (job stability, monthly salary, and having a management position), and incentive features (nonmonetary or monetary incentives received during the last year).

Finally, comparisons of differences in the four dimensions of satisfaction according to the identified predictor factors were done using the Mann-Whitney U-test. Statistical analyses were done using SPSS software version 20. Response bias was checked with a brief on-line survey sent to physicians who had not participated, asking about their overall career satisfaction, incentives received, age, gender and specialization.

\section{Results}

Of the 299 eligible physicians, 121 completed the questionnaire ( $40.7 \%$ response rate). The mean age was $41.08(\mathrm{SD}=6.68)$, with a median of 41 years-old. The gender distribution was $37.2 \%$ women and $62.8 \%$ men. The mean professional experience was 8.94 ( $\mathrm{SD}=6.03)$ years. The 21 specialties represented were grouped in four categories: $33.1 \%$ family practitioners, $35.5 \%$ medical and clinical specialists (Internal Medicine, Gastroenterology, Pediatrics, Intensive Care Medicine, etc.), $24 \%$ surgical and procedural specialists (Anesthesiology, Orthopedics, Obstetrics and Gynecology, General Surgery, etc.), and 7.4\% laboratory and technical specialists (Clinical Laboratory and Radiology); in addition, $17 \%$ of the physicians reported a second speciality, with Family Medicine as the most common one. In relation to incentive features, $47.9 \%$ of the physicians reported that they received from their hospitals monetary incentives during the last year (such as extra payments and bonus), while $33.1 \%$ physicians received nonmonetary incentives in the last twelve months (such as training courses, research grants, academic and courses grants, participation in academic and research groups). Furthermore, 35 physicians completed the brief online questionnaire and response bias was not detected.

The mean career satisfaction among the participant physicians was 4.36 ( $\mathrm{SD}=0.76)$, with a median of 4.56 ; in other words, the mean satisfaction was $72.7 \%$ (4.36 over 6.00 ) and median represents that half of the physicians have a satisfaction below or equal to $76 \%$ (4.56 over 6.00 ). The mean satisfaction by dimensions (Table 1) were: professional, 4.53 ( $\mathrm{SD}=0.92)$; inherent, 4.45 ( $\mathrm{SD}=0.74)$; performance, $4.39(\mathrm{SD}=0.77)$; and personal, 4.06 (SD=0.98).

The reliability of the questionnaire was verified through the Cronbach's alpha, obtaining good internal consistency reliabilities for the 16-item scale $(\alpha=0.92)$ and the four dimensions $(\alpha>0.77)$. Since the normality (ShapiroWilk Tests with $\mathrm{P}<0.001)$ and equality of variances (Levene $s$ Test=4.31, $\mathrm{P}=0.005$ ) assumptions were rejected, non-parametric tests were used to identify significant differences among the dimensions of career satisfaction. Thus, the Friedman's ANOVA test identified significant differences across the four dimensions of career satisfaction, $\chi^{2}(3)=55.18, \mathrm{P}<0.001$. Table 1 shows rating scores by dimension (median, interquartile range, and mean rank), and in Figure 1, box-plots of the four dimensions are compared. Post-hoc tests of significance for pair-wise comparisons, using the Wilcoxon Matched-Pairs Signed Rank tests, identified higher medians of professional, inherent and performance satisfaction in comparison to personal satisfaction $(\mathrm{P}<0.001)$. Professional satisfaction was greater than performance satisfaction $(\mathrm{P}<0.01)$. In contrast, no significant differences were detected between the inherent and the professional $(\mathrm{P}=0.05)$, and between the inherent and the performance $(\mathrm{P}=0.34)$ dimensions.

The logistic regression model identified two significant predictors of higher levels of career satisfaction (Table 2). Physicians who received non-monetary incentives during the

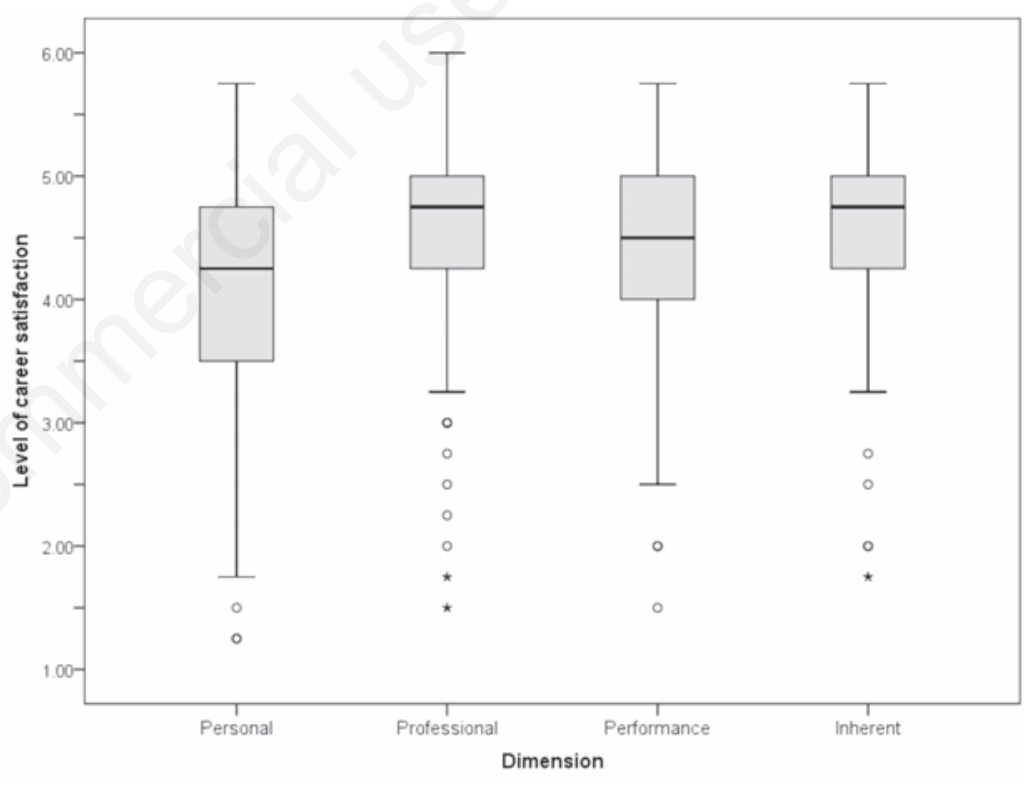

Figure 1. Box plots depict, by the four dimensions, different distributions of measured levels of career satisfaction. The personal satisfaction presents a higher variation than the professional, performance, and inherent dimensions. The median of the personal dimension appears to be lower than the other three. The circles and asterisks represent outliers and extreme outliers, respectively.

Table 1. Career satisfaction of physicians in Andalusia, Spain $(n=121)$.

\begin{tabular}{lccccccc} 
& Mean (SD) & Min & P25 & Median & P75 & Max & Mean rank \\
16-item scale & $4.36(0.76)$ & 1.75 & 4.03 & 4.56 & 4.84 & 5.63 & - \\
Dimension & & & & & & & \\
$\quad$ Personal & $4.06(0.98)$ & 1.25 & 3.50 & 4.25 & 4.75 & 5.75 & 1.85 \\
Professional & $4.53(0.92)$ & 1.50 & 4.25 & 4.75 & 5.00 & 6.00 & 2.96 \\
Performance & $4.39(0.77)$ & 1.50 & 4.00 & 4.50 & 5.00 & 5.75 & 2.53 \\
Inherent & $4.45(0.74)$ & 1.75 & 4.13 & 4.75 & 5.00 & 5.75 & 2.65 \\
\hline
\end{tabular}


last year and foreign physicians were 3.11 (C.I. $95 \%=1.19-8.13$ ) and 7.81 (C.I. $95 \%=1.40$ 43.48) times more likely to report a higher level of career satisfaction, respectively.

The Mann-Whitney U test identified significant median differences in personal $(\mathrm{U}=306$, $\mathrm{Z}=-3.04, \mathrm{P}=0.002, \mathrm{r}=-0.21)$ and performance $(\mathrm{U}=394, \mathrm{z}=-2.28, \mathrm{P}=0.02, \mathrm{r}=-0.21)$ dimensions of satisfaction when comparing foreign and locally trained physicians (Table 3). Between those who received non-monetary incentives and physicians who did not receive them during the last year, differences were identified in the professional $(\mathrm{U}=1167, \mathrm{z}=-$ 2.52, $\mathrm{P}=0.01, \mathrm{r}=-0.23$ ) and the performance $(\mathrm{U}=1239.5, \mathrm{z}=-2.12, \mathrm{P}=0.03, \mathrm{r}=-0.19)$ dimensions (Table 3).

\section{Discussion}

Previous studies in Andalusia have reported comparable levels of satisfaction among physicians: the study of the Andalusian Society of
Internal Medicine identified that $73.1 \%$ of the participants were satisfied with the work content; ${ }^{11}$ the study developed in the Axarquia Health District of Malaga, using the Font-Roja questionnaire, found a global mean job satisfaction of $64.4 \%$ (77.22 over 120);10 and, among pediatric surgeons, a mean job satisfaction of $58.7 \%$ (70.46 over 120) was reported using also the Font-Roja questionnaire. ${ }^{12}$ In the Primary Health Care district of Majorca, similar mean levels of job satisfaction have been identified among family practitioners and pediatricians, also assessed with the FontRoja scale (65 over 120).15 Furthermore, in Europe, studies have reported comparable levels of satisfaction. For instance in Switzerland and the Netherlands, an overall work satisfaction of $72.86 \%$ (5.1 over 7$)^{9}$ and $75.71 \%$ (5.3 over 7) ${ }^{19}$ were reported, respectively. Nevertheless, comparisons of these results with our study are limited due to differences in the perspective and scales used. Although, the results from the Canadian study could be comparable. ${ }^{16}$ Physicians in Canada appeared to be less satisfied (4.13) than in Andalusia (4.36).

Table 2. Factors associated with higher levels of career satisfaction $(n=121)$.

\begin{tabular}{lcc} 
Variables & Exp $(\beta)$ & $95 \%$ C.I. \\
Gender & 0.47 & $0.18-1.20$ \\
Age & 1.10 & $0.97-1.24$ \\
\hline Being a foreign physicians & $7.81^{*}$ & $1.40-43.48$ \\
Main speciality (ref. Family Medicine) & & \\
$\quad$ Medical and clinical & 2.85 & $0.99-8.20$ \\
$\quad$ Surgical and procedural & 0.85 & $0.26-2.83$ \\
$\quad$ Laboratory and technical & 0.30 & $0.05-1.69$ \\
\hline Having a second speciality (ref. none) & & \\
$\quad$ Family medicine & 0.16 & $0.02-1.17$ \\
$\quad$ Medical and clinical & 1.75 & $0.25-12.32$ \\
$\quad$ Laboratory and technical & 1.04 & $0.15-7.11$ \\
Years of experience & 0.93 & $0.82-1.06$ \\
\hline Having job stability & 0.44 & $0.10-1.89$ \\
Average monthly salary & 1.00 & $1.00-1.00$ \\
\hline Being in a chief position & 0.57 & $0.12-2.74$ \\
Having received monetary incentives & 1.08 & $0.47-2.49$ \\
\hline Having received non-monetary incentives & $3.11^{*}$ & $1.19-8.13$
\end{tabular}

By dimensions, practitioners in Canada were more satisfied with the inherent dimension (4.75) than in Andalusia (4.45); however, participant physicians in Andalusia were more satisfied with personal (4.06 vs. 3.84), professional (4.53 vs. 4.10) and performance dimensions (4.39 vs. 3.87 ) than physicians in Canada.

In relation to the differences identified among the dimensions of the career satisfaction, the personal dimension was the lowest, suggesting that participant physicians of Andalusia are having problems to keep work from intruding in their personal lives, sustain satisfying activities in the community, control their work schedule, and/or to be content with the way that administrative aspects of medical practice are handled. Similarly, this dimension was also reported as the lowest among the Canadian doctors. 16 On the other hand, the professional dimension scored high levels of satisfaction, which could be promoting some balance between the two dimensions of the basic-order needs. This is a relevant discrepancy among the dimensions of career satisfaction but, as Keeton et al. ${ }^{20}$ identified, physicians could remain satisfied with their careers despite having to struggle with a work-life balance. Notwithstanding, a disproportion in the dimensions of the career satisfaction is an imbalance in the satisfaction of physicians which could lead to distress, 3 leave direct patient care, ${ }^{5}$ burn-out, ${ }^{6}$ and leave medicine. ${ }^{4}$

Physicians, generally, work longer hours than the general population and under emotionally-charged situations; they also face increasing workloads, patient demands, and growing bureaucracy, ${ }^{7}$ that could negatively tip the effort-reward balance. This critical situation is especially susceptible in the current economic Spanish environment, which might be negatively affecting the well-being of the health human resources. This threatening environment is especially relevant, since physicians are making personal sacrifices to practice medicine, temporally compensated with professional contentment. Nonetheless, two relevant factors were identified with a higher level of career satisfaction: receiving

Table 3. Career satisfaction of physicians by identified predictor and dimensions ( $n=121)$.

\begin{tabular}{|c|c|c|c|c|c|c|c|c|c|c|}
\hline \multirow[t]{2}{*}{ Measure } & \multicolumn{2}{|c|}{$\begin{array}{l}\text { Foreign } \\
\text { physicians }\end{array}$} & \multicolumn{2}{|c|}{$\begin{array}{c}\text { Spanish } \\
\text { physicians }\end{array}$} & \multirow{2}{*}{$\begin{array}{l}\text { Mann-Whitney } \\
\text { U Statistic }\end{array}$} & \multicolumn{2}{|c|}{$\begin{array}{l}\text { Had non-monetary } \\
\text { incentives }\end{array}$} & \multicolumn{2}{|c|}{$\begin{array}{l}\text { Had not non-monetary } \\
\text { incentives }\end{array}$} & \multirow[t]{2}{*}{$\begin{array}{c}\text { Mann-Whitne } \\
\text { U Statistic }\end{array}$} \\
\hline & $\begin{array}{l}\text { Mean } \\
\text { (SD) }\end{array}$ & Median & $\begin{array}{l}\text { Mean } \\
\text { (SD) }\end{array}$ & Median & & Mean (SD) & Median & Mean (SD) & Median & \\
\hline 16-item scale & $4.76(0.71)$ & 4.91 & $4.31(0.76)$ & 4.56 & $386^{*}$ & $4.60(0.41)$ & 4.66 & $4.24(0.86)$ & 4.50 & $1233.5^{*}$ \\
\hline Personal & $4.77(0.73)$ & 4.88 & $3.98(0.97)$ & 4.25 & $306^{\circ}$ & $4.25(0.74)$ & 4.50 & $3.97(1.13)$ & 4.25 & 1398 \\
\hline Professional & $4.83(0.82)$ & 5.00 & $4.50(0.93)$ & 4.75 & 495.5 & $4.87(0.50)$ & 5.00 & $4.36(1.03)$ & 4.75 & $1167^{*}$ \\
\hline Performance & $4.81(0.64)$ & 5.00 & $4.35(0.78)$ & 4.50 & $394^{*}$ & $4.63(0.52)$ & 4.75 & $4.27(0.85)$ & 4.50 & $1239.5^{*}$ \\
\hline Inherent & $4.63(0.85)$ & 4.88 & $4.43(0.73)$ & 4.50 & 486 & $4.64(0.46)$ & 4.75 & $4.35(0.84)$ & 4.50 & 1319.5 \\
\hline
\end{tabular}

${ }^{*} \mathrm{P}<0.05 ;{ }^{\circ} \mathrm{P}<0.001$. 
non-monetary incentives and being a foreign physician.

The fact that physicians were more likely to report a higher level of career satisfaction when receiving non-monetary incentives, has organizational implications on how physicians' practice behaviors can be influenced to improve the quality of healthcare. In contrast, monetary incentives could increase physicians' perception of burden and negatively affect satisfaction of patients. ${ }^{21}$ In fact, monetary incentives have shown modest results, like the pay-per-performance program in Ontario, Canada.22

Healthcare policies are usually focused on monetary incentives and the non-monetary ones are neglected and underestimated. Given that motivation is influenced by both financial and non-financial incentives, ${ }^{23}$ non-financial alternatives should be more explored. This kind of alternative incentives need to be acknowledged because it has been found that the satisfaction of physicians can be enhanced when career growth and autonomy are increased, 19 along with time for continuing medical education. ${ }^{9}$ Moreover, the career satisfaction and commitment of physicians could be positively influenced by providing recognition, respect, empathy, and appreciation. ${ }^{24}$ As it was identified in this study, non-monetary incentives could positively affect high- and lowerorder needs of the physicians which could increase the probability of long-term positive effects among these professionals and health services provision.

Physicians are more likely to stay in practice, especially in rural and underserved areas, when they have personal satisfaction. ${ }^{25}$ Medical students consider the impact of a speciality on their personal life as a significant variable when choosing a career specialty; 26,27 new physicians are more attracted to choose a speciality which is offering them a controllable lifestyle. ${ }^{26}$ Personal satisfaction is a critical factor to promote professional satisfaction and it is important to create a limit between work and personal spheres; ${ }^{27}$ however, this limit is difficult to create, especially among female phyisicians. ${ }^{28}$ Physicians are aware of the required personal efforts that medicine has, accepting some trade-offs in their career-personal balance. Healthcare policies that recognize their personal desires need to be promoted to develop healthcare providers' well-being, looking above monetary rewards only. The GAIN strategy (Greater Access and Independence Now), developed in the Mayo Medical School and the Mayo Clinic, is an example of how physicians' satisfaction and productivity can be increased with non-financial incentives, while improving the patients access to health services. ${ }^{29}$

The evidence of foreign physicians being more likely to report a higher level of career satisfaction than their local counterparts could be related to their career achievements and self-evaluation in a foreign country. Foreign doctors use to evaluate their careers in the host country, taking into account previous experiences and opportunities from their countries of origin. This evaluation process leads to a positive influence on their personal and performance satisfaction. A considerable number of foreign physicians from Latin America work in Spain; 30 in fact, before the European economic crisis, physicians from Latin America, Africa, and Eastern Europe often considered Spain as a green pasture for their career development. However, economic downturns have directly affected the healthcare systems and working conditions of healthcare professionals in several European countries. Countries that traditionally were welcoming international professionals, like Spain, could be exposing their local and foreign physicians to important push factors to emigrate due to the anti-crisis policies. This situation could likely affect healthcare systems and their outcomes across several European countries.

Limitations of this study need to be acknowledged. First, the results cannot be extrapolated to the entire population of physicians in Spain. Second, it is recognized that not all hospitals in Andalusia participated in the study. Third, since this was a cross-sectional study, a cause and effect relation and sequence of events cannot be determined. Finally, despite the obtained response rate, it is important to consider that response bias was tested and found to be negligible. Future studies are recommended with bigger and stratified samples by specialty, rural and urban areas, and perhaps by autonomous communities. Furthermore, longitudinal studies evaluating the impact of monetary and non-monetary incentives on career satisfaction are recommended, as well as comparing the satisfaction of local and foreign trained physicians.

\section{Conclusions}

Career satisfaction has been measured among a sample of physicians from Andalusian hospitals, identifying that they scored the lowest levels in the personal dimension. This finding suggests that these physicians in Andalusian hospitals are making great personal sacrifices and are compensated by experiencing high levels of professional satisfaction in practicing medicine. This is an imbalance that, in the long term, could severely affect the well-being of these healthcare professionals and, subsequently, the quality of care that they are providing. Furthermore, non-monetary incentives for physicians demonstrated a sig- nificant impact on their satisfaction, influencing the professional and performance dimensions of career satisfaction. These results need to be considered when designing and implementing motivating strategies among physicians. In addition, foreign physicians have reported higher levels of satisfaction than their local counterparts, especially in their personal and performance satisfaction. This is a finding that deserves further investigation, particularly in times of crisis and transition where motivating factors are changing.

\section{References}

1. Smith S. Why are doctors so unhappy? BMJ 2001;322:1073-4.

2. Williams E, Skinner A. Outcomes of physician job satisfaction: a narrative review, implications, and directions for future research. Health Care Manage Rev 2003;28: 119-40.

3. Lepnurm R, Lockhart WS, Keegan D. A measure of daily distress in practising medicine. Can J Psychiatry 2009;54:170-80.

4. Landon B, Reschovsky J, Pham H, Blumenthal D. Leaving medicine: the consequences of physician dissatisfaction. Med Care 2006;44:234-42.

5. Hann M, Reeves D, Sibbald B. Relationships between job satisfaction, intentions to leave family practice and actually leaving among family physicians in England. Eur J Public Health 2011;21: 499-503.

6. Escribà-Agüir V, Artazcoz L, Pérez-Hoyos S. [Effect of psychosocial work environment and job satisfaction on burnout syndrome among specialist physicians]. Gac Sanit 2008;22:300-8. [Article in Spanish].

7. Wallace JE, Lemaire JB, Ghali WA. Physician wellness: a missing quality indicator. Lancet 2009;374:1714-21.

8. Leigh J, Kravitz R, Schembri M, et al. Physician career satisfaction across specialties. Arch Intern Med 2002;162:1577-84.

9. Bovier P, Perneger T. Predictors of work satisfaction among physicians. Eur J Public Health 2003;13:299-305.

10. Lomeña Villalobos J, Campaña Villegas F, Nuevo Toro G, et al. [Burnout and job satisfaction in primary care]. Medicina de Familia (And) 2002;5:147-55. [Article in Spanish].

11. Bernabeu-Wittel M, García-Morillo S, Pérez-Lázaro J, et al. Work, career satisfaction, and the position of general internists in the south of Spain. Eur J Intern Med 2005;16:454-60.

12. Jiménez Alvarez C, Morales Torres JL, Martínez Martínez C. [Study of burnout syndrome in Spanish pediatric surgeons]. Cir Pediatr 2002;15:73-8. [Article in 
Spanish].

13. Ruiz J, Martín M, Morillas J, et al. [Analysis of levels of professional satisfaction and view of the future of critical care medicine as a speciality]. Med Intensiva 2002;26:51-60. [Article in Spanish].

14. Chivato Pérez T, Campos Andreu A, Negro Alvarez JM, Caballero Martínez F. Professional burnout and work satisfaction in Spanish allergists: analysis of working conditions in the specialty. J Investig Allergol Clin Immunol 2011;21:13-21.

15. Esteva M, Larraz C, Jiménez F. [Mental health in family doctors: effects of satisfaction and stress at work]. Rev Clin Esp 2006;206:77-83. [Article in Spanish].

16. Lepnurm R, Danielson D, Dobson R, Keegan D. Cornerstones of career satisfaction in medicine. Can J Psychiatry 2006; 51:512-22.

17. Maslow AH. Motivation and personality. 2nd ed. New York: Harper and Row; 1970.

18. Peña-Sánchez JN, Delgado A, LucenaMuñoz JJ, Morales-Asencio JM. [Adapting and Validating in Spanish the 4CornerSAT Questionnaire to Measure Career Satisfaction of Specialized care Physicians.
Andalusia, Spain]. Rev Esp Salud Pública 2013;87:181-9. [Article in Spanish].

19. Roelen C, Koopmans P, Groothoff J. Which work factors determine job satisfaction? Work 2008;30:433-9.

20. Keeton K, Fenner D, Johnson T, Hayward R. Predictors of physician career satisfaction, work-life balance, and burnout. Obstet Gynecol 2007;109:949-55.

21. Gené-Badia J, Escaramis-Babiano G, SansCorrales $\mathrm{M}$, et al. Impact of economic incentives on quality of professional life and on end-user satisfaction in primary care. Health Policy 2007;80:2-10.

22. Li J, Hurley J, DeCicca P, Buckley G. Physician response to pay-for-performance: evidence from a natural experiment. NBER Working Paper No. 16909. Cambridge: The National Bureau of Economic Research; 2011. Available from: http:/www.nber.org/papers/w16909

23. Dieleman M, Cuong P, Anh L, Martineau T. Identifying factors for job motivation of rural health workers in North Viet Nam. Hum Resour Health 2003;1:10.

24. Deshpande SP, Demello J. An empirical investigation of factors influencing career satisfaction of primary care physicians. J Am Board Fam Med 2010;23:762-9.

25. Kelley M, Kuluski K, Brownlee K, Snow S. Physician satisfaction and practice intentions in Northwestern Ontario. Can J Rural Med 2008;13:129-35.

26. Dorsey ER, Jarjoura D, Rutecki GW. Influence of controllable lifestyle on recent trends in specialty choice by US medical students. JAMA 2003;290:1173-8.

27. Shanafelt TD, West CP, Poland GA, et al. Principles to promote physician satisfaction and work-life balance. Minn Med 2008;91:41-3.

28. Verlander G. Female physicians: balancing career and family. Acad Psychiatry 2004;28:331-6.

29. Brandt T, Romme C, LaRusso N, Lindor K. A novel incentive system for faculty in an academic medical center. Ann Intern Med 2002;137:738-43.

30. Martínez-Guevara C, Guiu-Barragán E, Ibáñez-Nolla J. [Past, present and future of the medical interculturality in emergency services]. Emergencias 2008;20: 131-4. [Article in Spanish]. 